\title{
Development Strategies for Higher Education Institutions Based on the Cultivation of Core Competitiveness
}

\author{
https://doi.org/10.3991/ijet.v16i21.26873 \\ Zhongyuan $\mathrm{Wu}^{1}$, Zheng Zhang ${ }^{2}(\varpi)$ \\ ${ }^{1}$ Yanching Institute of Technology, Langfang, China \\ ${ }^{2}$ Beijing International Studies University, Beijing, China \\ clark525210@163.com
}

\begin{abstract}
The development of higher education institutions is the inevitable path towards strong scientific research ability of higher education. Currently, under the impact of the strategies of developing world-class universities, and strengthening the core competitiveness of disciplines, higher education institutions in China are faced with immense challenges. Based on the cultivation of core competitiveness, this paper explores the evaluation and development strategies for the core competitiveness of higher education institutions. The results show that: core competitiveness is a comprehensive intangible ability, and improving core competitiveness helps to clarify the direction and enhancing the quality of talent training. The core competitiveness of China's higher education institutions has continued to improve, as evidenced by the growth in educational resources, educational fund, and scientific results. The core competitiveness of higher education can be evaluated by the following indexes: school-running philosophy, academic production capacity, management model innovation capacity, campus culture construction capacity, human resource management innovation capacity, and training model innovation capacity. The research results lay a theoretical basis for the reform of higher education institutions.
\end{abstract}

Keywords-higher education institutions, core competitiveness, development strategy, talent training, innovation ability

\section{Introduction}

Higher education has received more attention from people than ever before, and now the new era has posed even higher requirements for the development of education field $[1,2]$. In fact, the development of higher education not only should adapt to the needs of the country, but should pay attention to the development of international community, retain and develop the traditional features of the country, and cultivate talents with a global vision [3,4]. Now there's an upsurge of building "double firstclass" universities and disciplines in the education field in China, and the Chinese universities and colleges are making great efforts to optimize the structure of higher education, and improve the effect and quality of higher education [5]. At present, the 
serious lack of facilities, resources, and investment has brought great challenges to the development of higher education [6,7], and there're other problems such as the toolow proportion of expenditure for school personnel, and the resource allocation of higher education institutions does not conform to the law of development of higher education [8].

There are many types of higher education institutions such as development institutions, evaluation institutions, and supervision institutions [9]. The close cooperation of higher education institutions provides a guarantee for the connection and interaction among various components in the higher education system [10,11]. In China, these higher education institutions haven't fully played their roles, and the contradictions existing in the construction and research works of higher education have become more prominent in these days, and higher education institutions generally have problems such as dislocated functions, unclear boundaries, and mismatch between structures and functions, etc. [12, 13]. Despite of these unsolved issues, the comprehensive reform of higher education has made certain progress, acting as important organizations for studying the laws of higher education, higher education institutions have well played their role of "think tank" when providing theoretical support for colleges and universities and solving practical questions [14]. The development of higher education institutions could contribute to the full use of their functions, help to promote the scientific management of these institutions, and push forward the research of higher education [15].

The core competitiveness of higher education is essentially the capacity to optimize social objectives and achievements, and to maximize the created value $[16,17]$. The core competitiveness of higher education is unique to the disciplines, it is an integration of resources, knowledge, and abilities that can maintain a long-term competitive advantage $[18,19]$. Taking art or sports students for instance, their core competitiveness is to acquire knowledge, skills, and personal qualities through teaching, training, and extracurricular practical activities, and then excel in a certain aspect [20]. The core competitiveness of higher education aims to solve the employment issue of students, and the competence of students is directly related to their employability, employment quality, and career development, etc. [21]. Based on the cultivation of core competitiveness, this paper attempts to explore the evaluation of the core competitiveness of higher education institutions and propose targeted development strategies for them, in the hopes of providing a theoretical evidence for the reform of higher education institutions.

\section{Status quo of core competitiveness of higher education institutions}

\subsection{Analysis of status quo}

Higher education institutions in the United States started earlier and they are more mature than those in China [22]. Then, the changes in higher education and the scale of higher educational schools have promoted the development of the research work of 
colleges and universities, which has also urged the establishment of academic research institutions [23]. Higher education started in China during the period of the establishment of the nation, then it grows with the country and matures in recent years, however, the core competitiveness of higher education institutions in China still lags their counterparts in America [24]. Now in China, the responsibilities of higher education institutions are expanding, the researchers are more professional and the research methods are more scientific [25]. Table 1 lists the differences between higher education institutions in China and the United States. In terms of functional content, the Chinese higher education institutions mainly engage in theoretical research and specific administrative work, while the American higher education institutions directly assume the specific research projects of the schools; in terms of organization orientation, the Chinese higher education institutions are academic institutions, while the American higher education institutions are administrative institutions; in terms of research purpose, the research purpose of Chinese higher education institutions is mainly to develop academic theories, while the research purpose of American higher education institutions is to improve the management practice.

Table 1. Differences between higher education institutions in China and the United States

\begin{tabular}{|l|c|c|}
\hline Research object & China & United States \\
\hline Functional content & $\begin{array}{c}\text { Basic theories of education in the field } \\
\text { of higher education }\end{array}$ & Basic data and information \\
\hline Organization orientation & Academic institutions & $\begin{array}{c}\text { Andministrative agencies } \\
\text { transactional work }\end{array}$ \\
\hline Research purpose & Developing academic theory & Improving management practices \\
\hline
\end{tabular}

Figure 1 shows the gross enrollment rate of higher education institutions in China from 2013 to 2020 . The gross enrollment rate exhibits a gradual growth over the years. Compared with 2013, from 2014 to 2020, the gross enrollment rate increased by $5.98 \%, 7.75 \%, 29.9 \%, 32.7 \%, 49.6 \%, 58.1 \%$, and $58.8 \%$, respectively. Figure 2 shows the first-time employment rate of higher education institutions from 2013 to 2020. On the whole, the first-time employment rate was always above $87 \%$, the number kept around $90 \%$, showing an overall increasing trend over the years, it decreased slightly in 2015 and 2019, which is related to the policy environment of the country. 


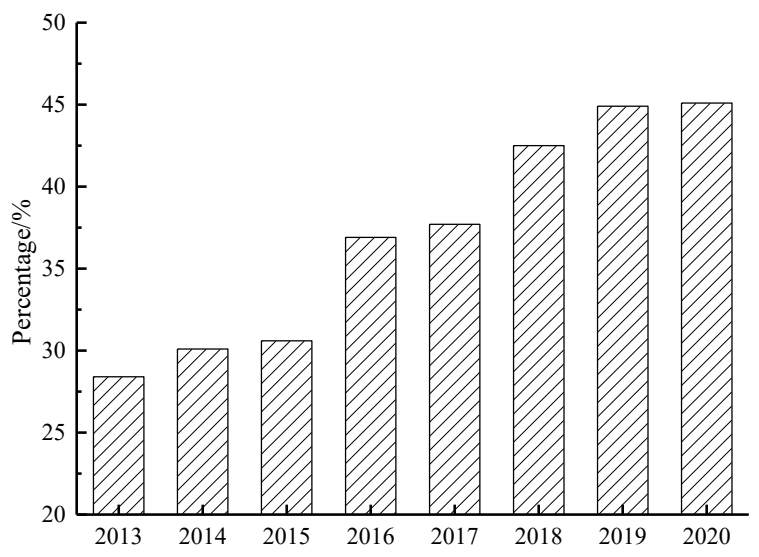

Fig. 1. Gross enrollment rate of higher education institutions, 2013-2020

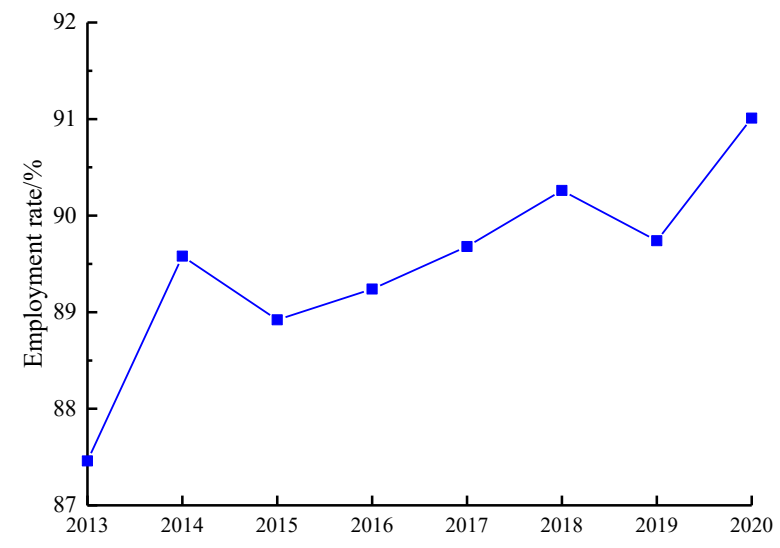

Fig. 2. First-time employment rate of higher education institutions, 2013-2020

\subsection{Analysis of problems}

In recent years, the national and provincial natural science foundation programs are carried out smoothly, and positive progress has been made in aspects of undertaken programs and published academic papers of higher educational institutions [26, 27]. Senior talents are the main force of the core competitiveness of higher education institutions. For the core competitiveness of higher education in some areas, there're still a bunch of problems, as listed in Figure 3, first, the research ability of higher education institutions is incompetent, a few colleges and universities are in a disadvantaged position across the country, their main manifestations include the low output and low transformation of educational research results. Second, the research forces of higher education are scattered and not integrated, cooperative research institutions can share resources, complement each other's advantages and disadvantages, thereby improving the effectiveness and efficiency of research. Third, there's a "generalization phenom- 
enon" with the higher education institutions, many colleges, universities, and higher education institutions have been regarded as administrative institutions, resulting in that many people do not have time for research works. Fourth, the research methods adopted by higher education institutions are not reasonable. Figure 4 analyzes the reasons for the problems existing in the core competitiveness of higher education institutions. First, many higher education institutions have a weak disciplinary foundation, researchers in these institutions do not have a solid theoretical foundation. Second, the research teams in higher education institutions generally have the characteristics of inter-discipline and multi-identity. Third, many higher education institutions have a weak research ability, with the increase of the number of doctoral graduates, there's an imbalance in the number of recruited doctors in higher educational institutions, institutions that ranked higher and with a stronger professional ability have more researchers, so the group effect is bigger, and the gap of research ability between institutions is obvious. Fourth, for many disciplines, there're too few research papers, and too few journals that can publish these papers, so it is slightly unfair in academic evaluation.

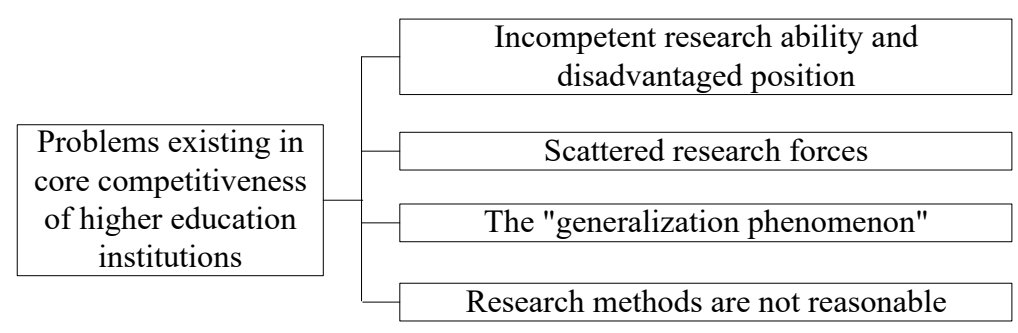

Fig. 3. Problems existing in core competitiveness of higher education institutions

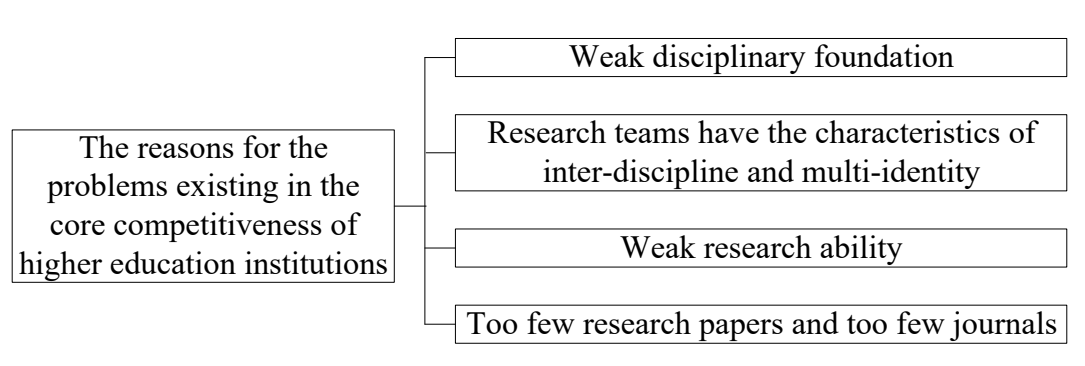

Fig. 4. Reasons for problems existing in the core competitiveness of higher education institutions

\section{Evaluation index system (EIS) proposal}

\subsection{Index selection principles}

Core competitiveness is a comprehensive intangible ability [28]. When selecting indexes for the evaluation of core competitiveness, the multi-dimensional hierarchical 
structure is usually adopted [29, 30]. Figure 5 lists the index selection principles, including the scientific principle, meaning that the selected indexes should have a theoretical basis and be able to reflect the core competitiveness of a discipline objectively and reasonably; the systematic principle, meaning that definite indexes should be selected from the levels and perspectives of the core competitiveness of the discipline, and the selected indexes should be able to reflect the core competitiveness of the disciplines comprehensively; the typical principle, meaning that the selected indexes should be suitable for the evaluation object, fully cover the core competitiveness of the discipline, and must contain the core competitiveness of the students of this discipline; the feasible principle, meaning that the selected indexes should conform to the actual objective level of the measurement object and can be quantified.

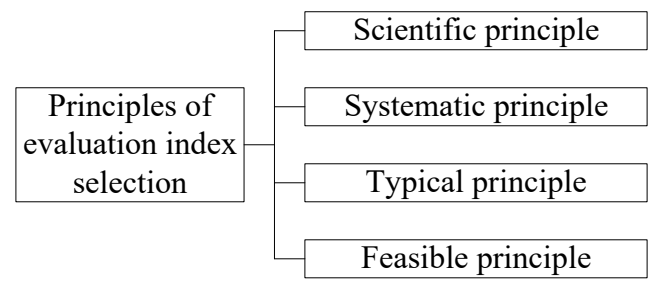

Fig. 5. Principle for selecting evaluation indexes of core competitiveness

\subsection{Index determination}

The research on the competitiveness of higher education is an extension of the research on the competitiveness of enterprises. Many domestic scholars conduct evaluations by establishing core competitiveness analysis indexes and evaluation indexes. Figure 6 shows the analysis indexes of the core competitiveness of higher education. The first-level indexes include school-running philosophy, academic production capacity, management model innovation capacity, campus culture construction capacity, human resource management innovation capacity, and training model innovation capacity. Under the first-level index school-running philosophy, the second-level indexes include the degree of specialization, the degree of people-oriented, and the degree of openness; second-level indexes under the first-level index academic production capacity include: discipline construction capacity, number of famous teachers, and knowledge production capacity; second-level indexes under the first-level index management model innovation capacity include: the degree of management integration, the degree of management informatization, and flexible management; the firstlevel index campus culture construction capacity has only one second-level index, the acquisition level of educational skills; second-level indexes under the first-level index human resource management innovation capacity include: teacher strength, coordination and communication skills, and human resource structure; second-level indexes under the first-level index training model innovation capacity include: the degree of reasonableness of training model, and the graduate employment quality.

Figure 7 shows the evaluation indexes of the core competitiveness of higher education institutions. The first-level evaluation indexes include: practice teachers' ethics, 
learn to teach, learn to educate people, and learn to develop. Figure 8 gives the evaluation results of the first-level indexes of the core competitiveness of higher education institutions. More than $80 \%$ of the people think that the index of "practice teachers' ethics" is very reasonable, more than $90 \%$ of the people think that the index of "learn to teach" is very reasonable, more than $80 \%$ of the people think that the index of "learn to educate people" is very reasonable, and more than $80 \%$ of the people think that the index of "learn to develop" is very reasonable. Figure 9 shows the evaluation results of the second-level indexes of the core competitiveness of higher education institutions. The evaluation pass rate of the second-level indexes exceeded $80 \%$.

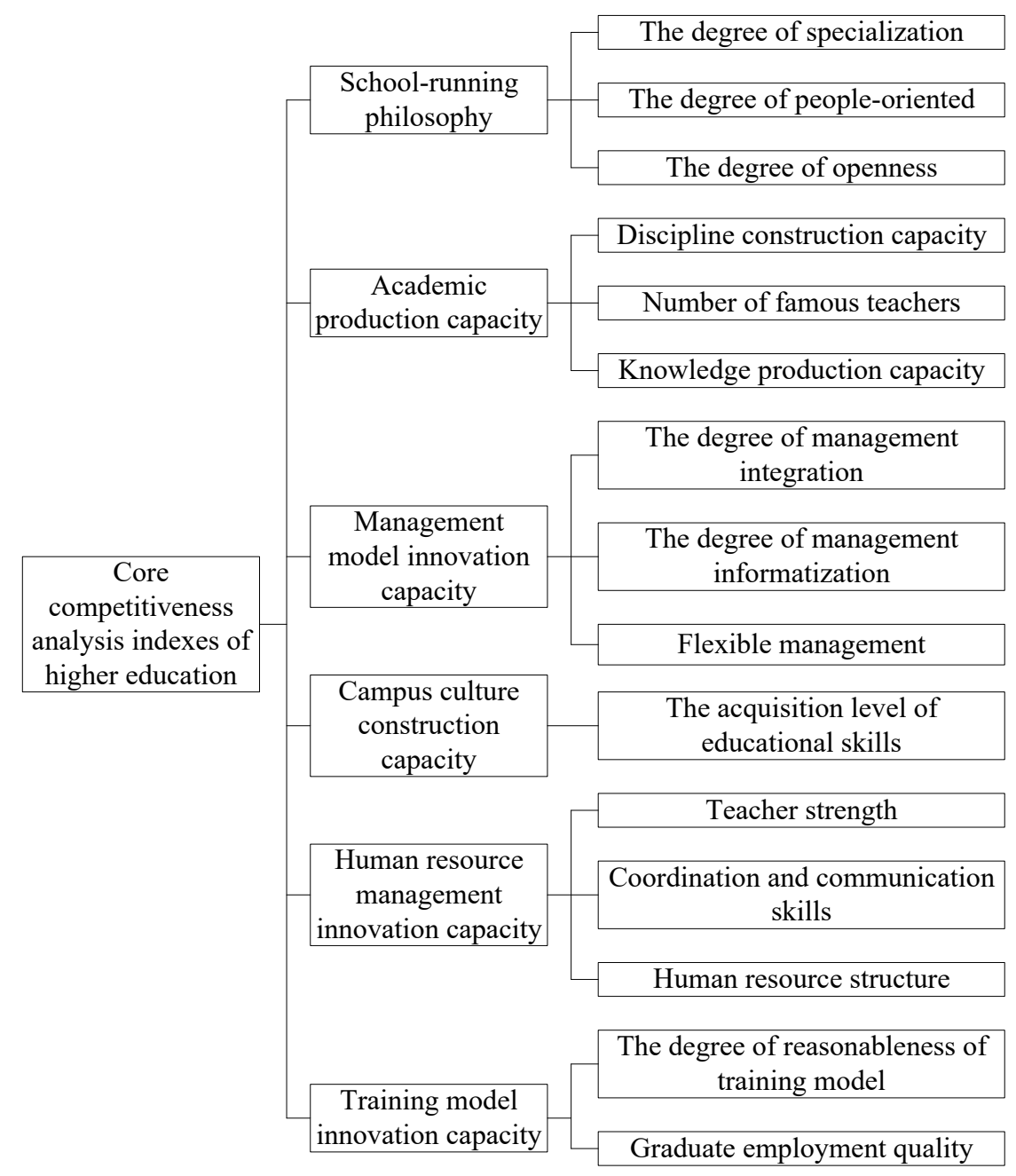

Fig. 6. Analysis indexes of core competitiveness of higher education 
Paper-Development Strategies for Higher Education Institutions Based on the Cultivation of Core ...

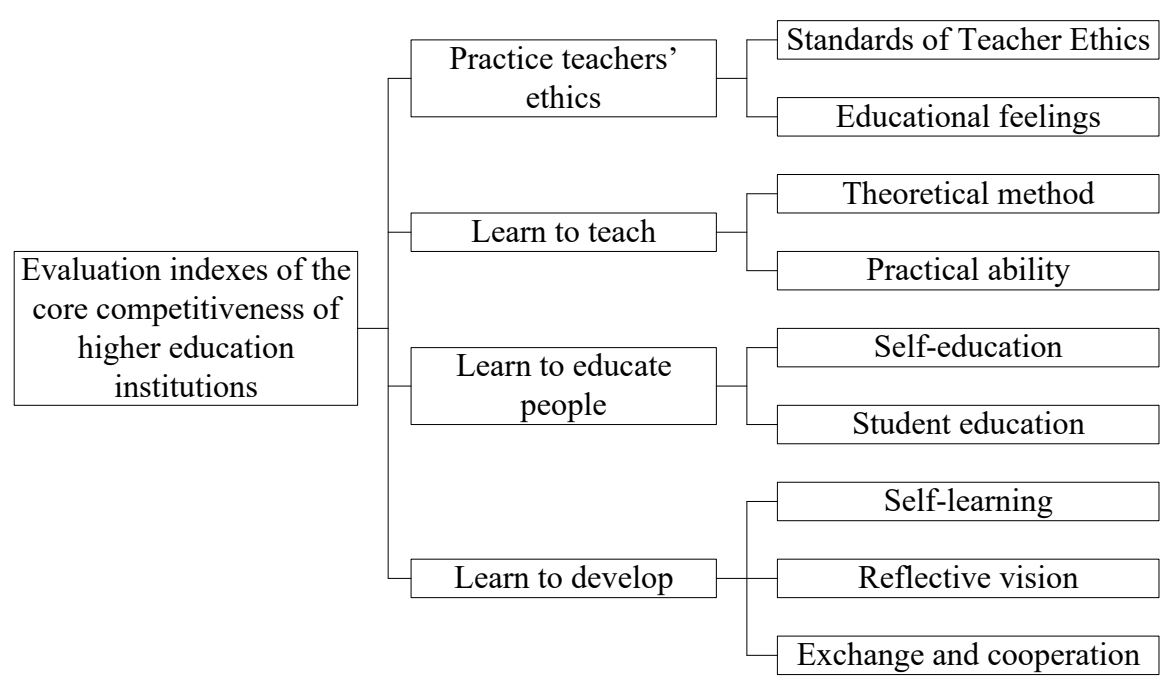

Fig. 7. Evaluation indexes of the core competitiveness of higher education institutions

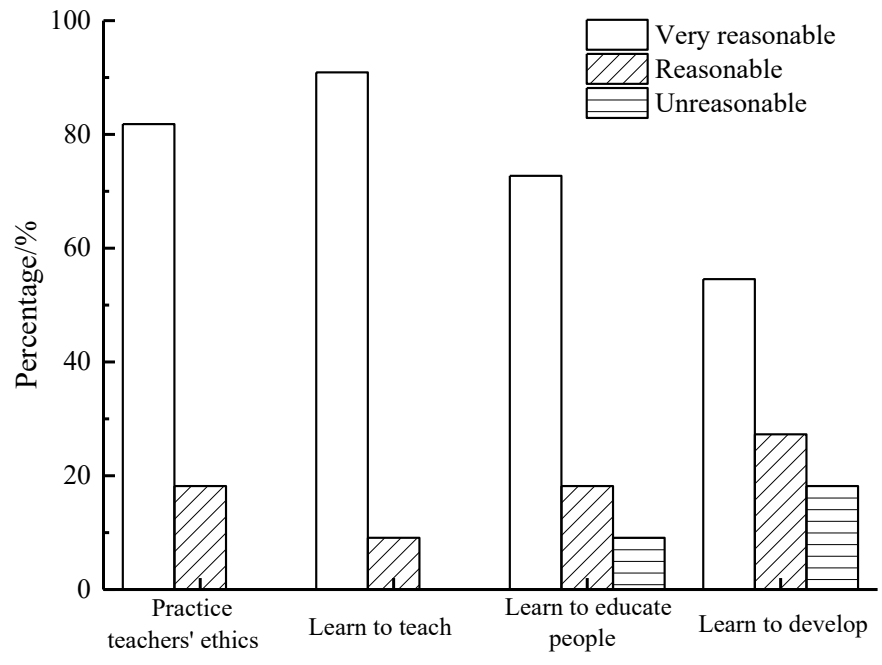

Fig. 8. Evaluation results of first-level indexes of core competitiveness of higher education institutions 


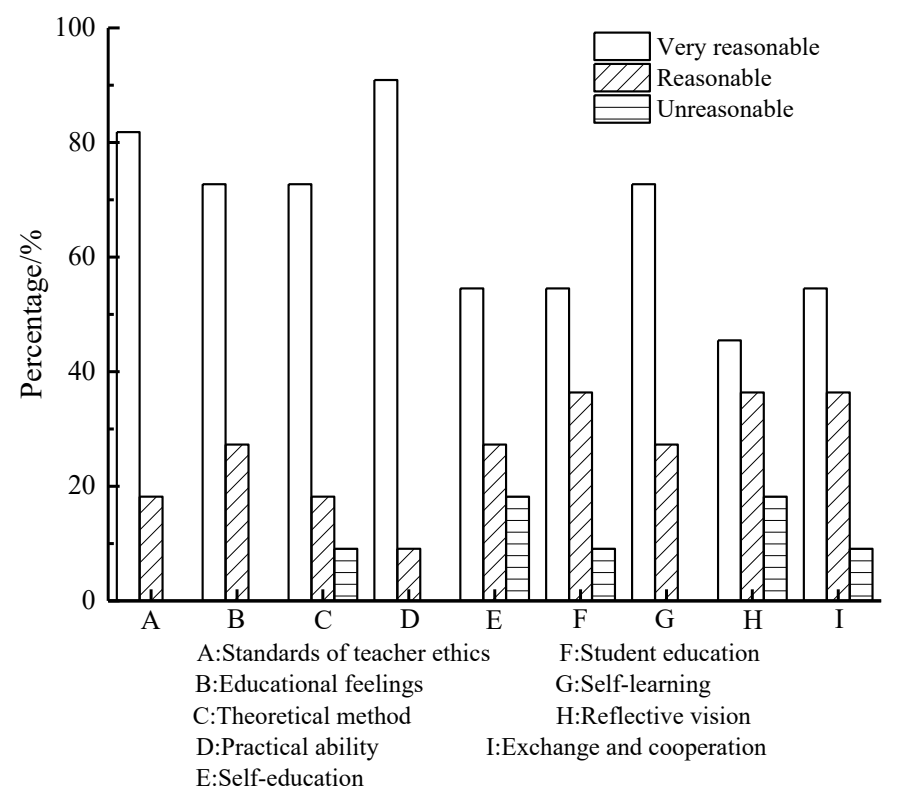

Fig. 9. Evaluation results of second-level indexes of core competitiveness of higher education institutions

\section{Evaluation of the core competitiveness of higher education institutions}

\subsection{Comparison of core competitiveness of higher education institutions}

There are many methods for evaluating the core competitiveness of higher education institutions, including the scientific research funding, scientific research strength, faculty strength, student enrollment, student employment quality, and student employment rate, etc. [31]. The strength of faculty reflects the number of teachers in a higher education institution; the strength of scientific research measures the ability of the higher education institution to develop and innovate the disciplines [32]. In this study, we defined five factors of core competitiveness, namely the enrollment scale, education efficiency, education resources, education funding, and scientific research strength. Then, our research team conducted questionnaire surveys in Shandong Province, Hubei Province, Henan Province, Anhui Province, Jiangxi Province, and Jiangsu Province to evaluate the core competitiveness of higher education institutions in each province. Figure 10 shows the scores of the core competitiveness of each province. Shandong Province ranked the top in terms of student enrollment scale; Hubei Province scored the highest in terms of education efficiency; Henan Province outperformed others in terms of education funding; and Jiangsu Province's scientific research strength was the best. 


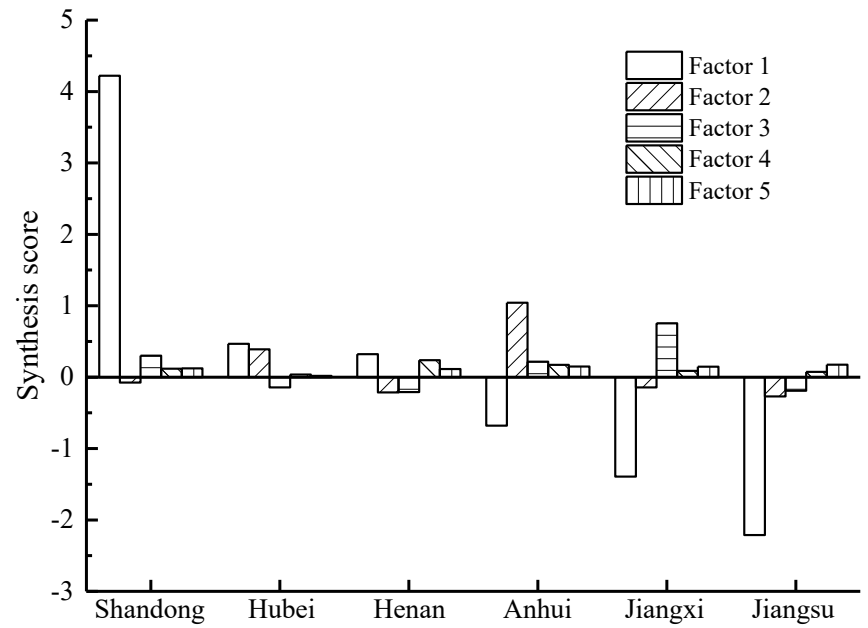

Fig. 10.Scores of the core competitiveness of each province

\subsection{Strategies for enhancing the core competitiveness of higher education institutions}

Higher education institutions are now working hard to strengthen their core competitiveness, some of them strive to enhance core competitiveness by attracting talents constantly, some concentrate on their advantageous disciplines to create double firstclass disciplines, however, during the overall development of the core competitiveness of higher education institutions, there're still many deviations and shortcomings, to cope with such defects, this paper proposed a few strategies for enhancing the core competitiveness of higher education institutions, as shown in Figure 11. First, strengthen the research teams, increase the number of professional researchers, especially interdisciplinary researchers; second, encourage researchers to conduct empirical research, promote cooperation between local double first-class institutions and key colleges and universities, and drive the transformation and development of independent institutions; third, enhance research strength of higher education institutions, clarify their positions and functions, and actively motivate people who are interested in higher education research to participate in the cooperative research teams, also, measures such as setting up full-time research positions, increasing the number of researchers, and forming research teams could be taken to enhance the research level of higher education institutions; fourth, foster academic exchanges among colleges and universities and accelerate platform construction, for institutions with good scientific research strength, urge them to hold academic conferences and seminars, and join their efforts to create core journals; fifth, optimize the guarantee system for the research work of higher education institutions, realize integration of various institutions with government taking the lead, and local governments should give more support for advantageous colleges and universities. 


\begin{tabular}{|c|}
\hline $\begin{array}{c}\text { Strategies for enhancing } \\
\text { the core competitiveness } \\
\text { of higher education } \\
\text { institutions }\end{array}$ \\
\hline $\begin{array}{c}\text { Encourage researchers to conduct empirical } \\
\text { research }\end{array}$ \\
\hline $\begin{array}{c}\text { Foster academic exchanges and accelerate } \\
\text { platform construction }\end{array}$ \\
\hline $\begin{array}{c}\text { Optimize the guarantee system for the } \\
\text { research of higher education }\end{array}$ \\
\hline
\end{tabular}

Fig. 11. Strategies for enhancing the core competitiveness of higher education institutions

\section{Conclusions}

Based on the cultivation of core competitiveness, this paper studied the evaluation and development strategies of the core competitiveness of higher education institutions. The specific conclusions are as follows:

1. Compared with 2013, from 2014 to 2020, the gross enrollment rate of higher education institutions in China increased by $5.98 \%, 7.75 \%, 29.9 \%, 32.7 \%, 49.6 \%$, $58.1 \%$, and $58.8 \%$, respectively, and the first-time employment rate also showed an overall increasing trend.

2. The first-level analysis indexes of the core competitiveness of higher education include school-running philosophy, academic production capacity, management model innovation capacity, campus culture construction capacity, human resource management innovation capacity, and training model innovation capacity. The first-level evaluation indexes of the core competitiveness of higher education institutions include practice teachers' ethics, learn to teach, learn to educate people, and learn to develop.

3. In the future, the core competitiveness of higher education institutions can be improved by strengthening the research teams of higher education institutions, encouraging researchers to conduct empirical research, enhancing research strength of higher education institutions, and optimizing the guarantee system for the research work of higher education institutions, etc.

\section{Acknowledgment}

The project of research and practice of higher education teaching reform in Hebei Province, China "research and practice of talent training program in private colleges based on meeting diverse needs". 


\section{$7 \quad$ References}

[1] Weiland-Bräuer, N., Prasse, D., Brauer, A., Jaspers, C., Reusch, T.B., Schmitz, R.A. (2020). Cultivable microbiota associated with Aurelia Aurita and Mnemiopsis leidyi. MicrobiologyOpen, 9(9): e1094. https://doi.org/10.1002/mbo3.1094

[2] Tabucanon, A.S., Sahavacharin, A., Rathviboon, S., Lhaetee, H., Pakdeesom, D., Xue, W., Charmondusit, K. (2021). Investigating the critical issues for enhancing sustainability in higher education institutes in Thailand. International Journal of Sustainable Development and Planning, 16(3): 503-514. https://doi.org/10.18280/ijsdp.160311

[3] Pedro, E.D.M., Leitão, J., Alves, H. (2020). Stakeholders' Perceptions of Sustainable Development of Higher Education Institutions: An Intellectual Capital Approach. International Journal of Sustainability in Higher Education, 21(5): 911-942. https://doi.org/ 10.1108/IJSHE-01-2020-0030

[4] Ashour, A.F. (2020). Design responsibility and sustainability in education. International Journal of Design \& Nature and Ecodynamics, 15(1): 129-133. https://doi.org/10. 18280/ijdne. 150117

[5] Findler, F., Schönherr, N., Lozano, R., Reider, D., Martinuzzi, A. (2019). The impacts of higher education institutions on sustainable development: A review and conceptualization. International Journal of Sustainability in Higher Education., 20(1): 23-38. https://doi. org/10.1108/IJSHE-07-2017-0114

[6] Al-Husban, N.A., Shorman, S. (2020). Perceptions of Syrian Student Refugees towards Blended Learning: Implications for Higher Education Institutions, International Journal of Emerging Technologies in Learning, 15(1), 45-60. https://doi.org/10.3991/ijet.v15i01 .11431

[7] Wen, J., Wei, X.C., He, T., Zhang, S.S. (2020). Regression analysis on the influencing factors of the acceptance of online education platform among college students. Ingénierie des Systèmes d'Information, 25(5): 595-600. https://doi.org/10.18280/isi.250506

[8] Saha, A.K., Al-Shaer, H., Dixon, R., Demirag, I. (2021). Determinants of carbon emission disclosures and UN sustainable development goals: the case of UK higher education institutions. Australian Accounting Review, 31(2): 79-107. https://doi.org/10.1111/auar.12324

[9] Suanj, Z., Jakopec, A., Ori, A. (2020). Academics' effectiveness and professional development in croatia: challenges for human resource management in higher education institutions. European Journal of Education, 55(4): 476-488. https://doi.org/10.1111/ejed.12422

[10] Antonova, N.V., Shmeleva, Z.N., Kozulina, N.S. (2020). Lifelong learning as the way of modern personality development in Russia on the example of higher educational institution of technical and natural-scientific profile. In Journal of Physics: Conference Series, 1691(1): 012146. https://doi.org/10.1088/1742-6596/1691/1/012146

[11] Khan, C.T. (2018). The inferences \& nature of china's transfer and development of technology from higher education institutions to industry. Open Journal of Social Sciences, 6(9): 12-34. https://doi.org/10.4236/jss.2018.69002

[12] Bakhtina, O.Y., Kirillov, A.V., Matyash, S.A., Urzha, O.A. (2015). The development of technology for higher education institution's administrative personnel assessment. International Education Studies, 8(5): 179-190. https://doi.org/10.5539/ies.v8n5p179

[13] Kanyimba, A., Hamunyela, M., Kasanda, C.D. (2014). Barriers to the implementation of education for sustainable development in namibia's higher education institutions. Creative Education, 5(4): 242-252. https://doi.org/10.4236/ce.2014.54033

[14] Lillis, D., Lynch, M. (2013). New challenges for strategy development in Irish higher education institutions. Higher Education Policy, 27(2): 279-300. https://doi.org/10.1057/hep. $\underline{2013.23}$ 
[15] Castro, D., Tomàs, M. (2011). Development of Manager-Academics at Institutions of Higher Education in Catalonia. Higher Education Quarterly, 65(3): 290-307. https://doi.org/10.1111/j.1468-2273.2011.00490.x

[16] Leibowitz, B., Bozalek, V., Van Schalkwyk, S., Winberg, C. (2015). Institutional context matters: The professional development of academics as teachers in South African higher education. Higher Education, 69(2): 315-330. https://doi.org/10.1007/s10734-014-9777-2

[17] He, Z., Hao, G. (2014). Physical Education Reform and Development in Regular Institutions of Higher Learning under the Vision of Modern Great Education. Advances in Physical Education, 4(1): 36. https://doi.org/10.4236/ape.2014.41006

[18] Whittaker, J.A., Montgomery, B.L. (2014). Cultivating institutional transformation and sustainable stem diversity in higher education through integrative faculty development. Innovative Higher Education, 39(4): 263-275. https://doi.org/10.1007/s10755-013-9277-9

[19] Cruz, O.D. (2019). Perceptions of higher agricultural education toward sustainable agricultural development. Higher Education, Skills and Work-Based Learning, 10(1): 187-202. https://doi.org/10.1108/heswbl-06-2019-0080

[20] Munguatosha, G.M., Muyinda, P.B., Lubega, J.T. (2011). A social networked learning adoption model for higher education institutions in developing countries. On the Horizon, 19(4): 307-320. https://doi.org/10.1108/10748121111179439

[21] Hodgkinson-Williams, C., Slay, H., Siebrger, I. (2010). Developing communities of practice within and outside higher education institutions. British Journal of Educational Technology, 39(3): 433-442. https://doi.org/10.1111/j.1467-8535.2008.00841.x

[22] Bai, L., Millwater, J., Hudson, P. (2013). Workplace influences on Chinese TEFL academics' development as researchers: a study of two Chinese higher education institutions. Research in Post-Compulsory Education, 18(4): 415-430. https://doi.org/10.1080/13596748 .2013 .847233

[23] Panagiotakopoulos, A. (2012). Employability skills development in Greek higher education institutions (HEIs): Implications for policy makers. Higher education, skills and workbased learning. https://doi.org/10.1108/20423891211224621

[24] Voorhees, R. A., Harvey, L. (2010). Higher education and workforce development: a strategic role for institutional research. New Directions for Institutional Research, 2005(128): 5-12. https://doi.org/10.1002/ir.159

[25] Khasawneh, S. (2011). Learning organization disciplines in higher education institutions: an approach to human resource development in Jordan. Innovative Higher Education, 36(4): 273-285. https://doi.org/10.1007/s10755-010-9170-8

[26] Case, A.S.A., Mugwanya, R., Marsden, G., Boateng, R. (2011). A preliminary study of podcasting in developing higher education institutions: A south African case. Journal of Systems \& Information Technology, 13(3): 268-285. https://doi.org/10.1108/1328726 $\underline{1111164853}$

Jenkins, M., Browne, T., Walker, R., Hewitt, R. (2011). The development of technology enhanced learning: findings from a 2008 survey of UK higher education institutions. Interactive Learning Environments, 19(5): 447-465. https://doi.org/10.1080/1049482090348 $\underline{4429}$

[28] Machado, C. (2010). Developing an e-readiness model for higher education institutions: results of a focus group study. British Journal of Educational Technology, 38(1): 72-82. https://doi.org/10.1111/j.1467-8535.2006.00595.x

[29] Wehrmeyer, W., Chenoweth, J. (2006). The role and effectiveness of continuing education training courses offered by higher education institutions in furthering the implementation of sustainable development. International Journal of Sustainability in Higher Education, 7(2): 129-141. https://doi.org/10.1108/14676370610655913 
[30] Finnveden, G., Friman, E., Mogren, A., Palmer, H., Svärd, L. (2020). Evaluation of integration of sustainable development in higher education in Sweden. International Journal of Sustainability in Higher Education, 21(4): 685-698. https://doi.org/10.1108/ijshe-09-2019$\underline{0287}$

[31] Aleixo, A.M., Azeiteiro, U., Leal, S. (2018). The implementation of sustainability practices in Portuguese higher education institutions. International Journal of Sustainability in Higher Education., 9(1): 146-178. https://doi.org/10.1108/ijshe-02-2017-0016

[32] Daly, E., Mohammed, D., Boglarsky, C., Blessinger, P., Zeine, R. (2019). Interaction Facilitation and Task Facilitation need optimization in higher education institutions. Journal of Applied Research in Higher Education. 12(3): 403-412. https://doi.org/10.1108/jarhe$\underline{04-2018-0062}$

\section{Authors}

Zhongyuan Wu, master of education management, Beijing Normal University; The Dean of School of international education, Yanching Institute of Technology. He has won many honors such as "excellent teacher in Hebei Province, member of talent pool of backbone counselors in Colleges and universities in Hebei Province, excellent instructor of the Fifth National College Students' art exhibition, third prize of Hebei counselor skills competition" and so on; Presided over one project of the 12th Five Year Plan of Educational Science in Hebei Province, participated in two projects of the Department of education of Hebei Province and two school level projects. Participated in the compilation of military education for college students, college experience English counseling course and student management and mental health education. The paper gives an account of the influence of audio-visual input information on College Students' English listening ability from the perspective of interactive cognitive mode. The paper has 10 chapters, including the "EQ education and the daily psychological work of college students", and the construction of the long term tact of College Students' Ideological and Political Education under the Internet plus background (Email: wuclark@126.com).

Zheng Zhang is a master of English linguistics at Beijing International Studies University, North Arizona University, and head of the Department of international education, Beijing International Studies University.4 papers on the teaching of College English listening under the guidance of the multidimensional interaction theory and the construction of long term tact in the ideological and political education of College Students under the Internet plus background. Editor in chief of textbooks: IELTS standard textbook reading, new TOEFL standard course: Writing.

Article submitted 2021-09-06. Resubmitted 2021-10-10. Final acceptance 2021-10-12. Final version published as submitted by the authors. 